\title{
How urban density, network topology and socio-economy influence public transport ridership: Empirical evidence from 48 European metropolitan areas
}

\author{
Ingvardson, Jesper Bláfoss; Nielsen, Otto Anker
}

Published in:

Journal of Transport Geography

Link to article, DOI:

10.1016/j.jtrangeo.2018.07.002

Publication date:

2018

Document Version

Peer reviewed version

Link back to DTU Orbit

Citation (APA):

Ingvardson, J. B., \& Nielsen, O. A. (2018). How urban density, network topology and socio-economy influence public transport ridership: Empirical evidence from 48 European metropolitan areas. Journal of Transport Geography, 72, 50-63. https://doi.org/10.1016/j.jtrangeo.2018.07.002

\section{General rights}

Copyright and moral rights for the publications made accessible in the public portal are retained by the authors and/or other copyright owners and it is a condition of accessing publications that users recognise and abide by the legal requirements associated with these rights.

- Users may download and print one copy of any publication from the public portal for the purpose of private study or research.

- You may not further distribute the material or use it for any profit-making activity or commercial gain

- You may freely distribute the URL identifying the publication in the public portal 

48 European metropolitan areas

Abstract

Understanding the determinants of public transport ridership is important in order to plan attractive public transport systems efficiently. This study analyses at a meta-level per capita public transport ridership across 48 European cities based on a rich database collected as part of this study. The dataset includes detailed mode-specific information about the public transport networks, hence extending previous research by analysing each public transport mode separately while simultaneously taking into account the main determinants of ridership identified by a thorough literature review of 36 previous studies, e.g. urban demographics and land uses. Factor analysis was deployed revealing four main composite determinants, namely i) metro coverage, network connectivity, and urban density, ii) suburban rail coverage, iii) economic inequality, and iv) light rail coverage. Subsequent multiple regression analysis confirmed the a priori hypothesis of per capita ridership being positively associated with the extent of network coverage in terms of metro, suburban rail and light rail transit. The importance of network connectivity was included with results suggesting that the number of transfer stations was more important than the cyclomatic number of the public transport network. Cities with higher economic inequality in terms of higher unemployment, lower per capita GDP and higher GINI-coefficient showed lower public transport ridership. Finally, the analyses highlighted the importance of proper definitions of urban areas in order to perform consistent analyses of data across cities. This revealed the impact on transit ridership of urban density defined as population and especially job intensity per $\mathrm{km}^{2}$. As the study is based on aggregate, cross-sectional data from a relatively small sample of European cities, it is not without limitations in terms of mainly revealing correlational structures rather than causations as well as not including all variables related to public transport ridership. Future studies should further investigate these interrelationships before drawing conclusions on the causational relationships.

\section{Key words}

Public transport ridership, network topology, factor analysis, urban density, rail factor 


\section{Introduction}

Attractive public transport systems are more and more important in ensuring mobility in the increasingly congested metropolitan areas. Knowing the key drivers for attracting passengers is essential when developing successful public transport systems.

Much research has been devoted to analysing the main determinants of ridership (Taylor and Fink, 2013). Studies have ranged from focusing on single lines based on data on the individual level, e.g. Buehler (2011), or aggregate data, e.g. Cervero et al. (2010); Chen et al. (2010), to covering larger metropolitan areas using aggregate characteristics, e.g. Gutiérrez et al. (2011); Kuby et al. (2004); Taylor et al. (2009). Other studies have compared determinants across different countries to highlight potential differences and similarities, e.g. Buehler (2011); Currie et al. (2011); Loo et al. (2010). These studies include factors related to the public transport system itself in terms of general level of service, travel costs and accessibility as well as external factors such as the socio-economic characteristics of the study area and the availability and characteristics of alternative modes (Chen et al., 2010; Jun et al., 2015; Syed and Khan, 2000; Taylor et al., 2009). Focusing on public transport systems, key determinants have been identified including service coverage in terms of high accessibility and frequent service resulting in low travel times. Such improvements have been shown to be more important than pricing (Taylor and Fink, 2013), hence suggesting the importance of accounting for spatial variation.

Another important parameter for public transport ridership is the network connectivity and the interaction between different public transport networks. Much research has focused on analysing public transport network connectivity on the micro-scale focusing on level of service (Ceder et al., 2009; Hadas and Ranjitkar, 2012) and transport equity (Kaplan et al., 2014), and on a macro-scale evaluating the general network topology (Derrible and Kennedy, 2010; Sienkiewicz and Hoo, 2005) and resilience in cases of disruption, e.g. Cadarso et al. (2013); Cats (2016); Zhang et al. (2015). However, research on the influence of macro-scale connectivity measures on ridership is limited. Derrible and Kennedy (2009) showed a positive influence of network topology indicators of connectivity on ridership using data from 19 subway networks, and Sohn and Shim (2010) found connectivity to be influential on station boarding on the Seoul subway system. While both studies highlight the importance of connectivity they do have shortcomings in either only using data from a single network (Sohn and Shim, 2010) or not controlling for other important determinants of ridership (Derrible and Kennedy, 2009).

The present study addresses these previous shortcomings by analysing public transport ridership across 48 European metropolitan areas taking into account characteristics related to the traffic systems and the urban areas. The overall aim is to investigate the influence of various rail networks on per capita use frequency of the public transport system. The contribution is three-fold.

Firstly, the main determinants of public transport ridership are identified via a thorough review of previous research. This allows for formulating a ridership model capable of analysing the correlation with network characteristics while taking into account other main determinants. Secondly, this study 
to investigate possible differences in attractiveness. This makes it possible to analyse the relative significance of different modal networks. Thirdly, the focus on network topology allows for analysing whether network topology better explains per capita ridership as compared with simple service coverage characteristics such as number of stations and length of network.

The remainder of this paper is structured as follows. Section 2 reviews the literature on the determinants of public transport ridership. In section 3 the data sources and measures used for the modelling are described. The analytical approach and results are presented in Section 4 while section 5 concludes the work by highlighting relevant implications.

\section{Literature review}

Most studies have investigated the determinants of public transport ridership by focusing on the influences of land uses, built environment, public transport characteristics and socio-economic characteristics.

Many studies have deployed an ordinary least square (OLS) regression approach (Cordera et al., 2015; Guerra et al., 2012; Gutiérrez et al., 2011; Kuby et al., 2004; Liu et al., 2014; Loo et al., 2010; Sohn and Shim, 2010; Souche, 2010; Sung and Oh, 2011; Zhao et al., 2013). This method is simple, but assumes uniformity over the study area. Hence, geographically weighted regression (GWR) models have been suggested to better account for the spatial variation between public transport ridership and explanatory variables (Cardozo et al., 2012; Chiou et al., 2015; Chow et al., 2006; Jun et al., 2015). Two-stage least square (2SLS) has been proposed to take into account correlation between the dependent variable and independent variables (Cordera et al., 2015; Estupiñán and Rodríguez, 2008; Souche, 2010; Taylor et al., 2009). Several studies have compared the methods for different purposes. In a study from Florida Chow et al. (2006) found that GWR models better predicted transit use among commuters than simple OLS. Similarly, Blainey (2010) found that GWR was better than linear and loglinear regression in estimating annual boadings at local rail staions in England and Wales. And Cardozo et al. (2012) found that GWR gave a better fit than OLS in modelling boardings of Madrid metro.

A summary of explanatory variables and their influence on public transport ridership are shown in Table $1^{1}$. The studies all analyse ridership, but use different measures such as number of boardings for bus stops (Cervero et al., 2010; Pulugurtha and Agurla, 2012), light rail stations (Gordon and Willson, 1984; Kuby et al., 2004), metro stations (Cardozo et al., 2012; Gutiérrez et al., 2011; Jun et al., 2015; Loo et al., 2010; Sohn and Shim, 2010; Zhang and Wang, 2014; Zhao et al., 2013), or a combination (Cervero, 1996; Guerra et al., 2012; Liu et al., 2014). Other studies have analysed public

1 Note that some parameters were grouped to fit in the table, e.g. service frequency and service headway (but reversing the sign of headway to make it compatible with service frequency) and socio-economic characteristics such as gender, age, racial, ethnic, and educational background (assigning "+/_" as the effects differed across studies). Parameters that could not easily be grouped and which were only found in a single study were omitted in Table 1. This included variables such as age of buses (Chiou et al., 2015), years of operation (Loo et al., 2010), electrification (Blainey, 2010), and number of station entrances (Sung et al., 2014). 
transport usage rates (Buehler, 2011; Chiou et al., 2015; Chow et al., 2006; Cordera et al., 2015; Derrible and Kennedy, 2009; Taylor et al., 2009), and aggregate public transport ridership per route (Chen et al., 2010; Currie et al., 2011; Currie and Delbosc, 2011; Rahman and Balijepalli, 2016), or as flows between O-D pairs (Choi et al., 2012; Thompson et al., 2012). Hence, the studies highlighted in Table 1 range from focusing on station-level ridership over line- or corridor-level ridership to full network ridership. Most studies reported the same findings. Population and employment densities are important determinants of ridership, although they have been included in different forms across studies. In Souche (2010) a simple urban density measure was significantly positively associated with ridership, whereas most other studies investigated the effects of population and employment separately using simple densities. The effects of specific employment densities have also been investigated, e.g. office area (Choi et al., 2012; Sohn and Shim, 2010; Sung et al., 2014; Zhao et al., 2013), commercial area (Cervero and Murakami, 2008; Loo et al., 2010; Pulugurtha and Agurla, 2012; Sohn and Shim, 2010; Sung et al., 2014; Sung and Oh, 2011), retail area (Zhang and Wang, 2014; Zhao et al., 2013), institutions (Pulugurtha and Agurla, 2012), and educational facilities (Choi et al., 2012; Zhao et al., 2013). These were all related to higher ridership. Similar positive effects have been found for specific land uses such as entertainment venues (Zhao et al., 2013), airports (Guerra et al., 2012; Kuby et al., 2004), and harbours (Blainey, 2010). Other studies found a positive effect of being located in the CBD or city centre, or a negative distance effect, further highlighting the influence of denser areas on ridership. Furthermore, walkable areas surrounding stations were found to be strongly related to increased public transport use in several studies (Estupiñán and Rodríguez, 2008). On the other hand, land uses with less travel demand such as industry and garage areas had negative effects on ridership (Loo et al., 2010; Pulugurtha and Agurla, 2012; Zhang and Wang, 2014). Finally, the influence of mixed land uses were found to be positively related in many studies, e.g. Gutiérrez et al. (2011), but with some studies finding inconsistent effects across different study areas (Buehler, 2011; Sung et al., 2014).

Among individual socio-economic characteristics income was generally found to be significant. Generally, a negative income effect was reported suggesting lower ridership among higher-income households. In some studies this effect was observed by a positive effect of the percentage of lowincome households (Chiou et al., 2015; Taylor et al., 2009) or of a proxy indicator such as percent renters (Kuby et al., 2004). However, Zhang and Wang (2014) found a positive relationship between average household income and station ridership for the Manhatten subway network, which was due to an increased general travel frequency. And Cervero (1996) found that income is only significant for the more expensive commuter rail, and not for light rail, possibly due to higher fare levels. Unemployment was found significant in several studies, mostly with a negative effect on ridership. However, in Cordera et al. (2015) a positive effect was observed in Spain during the financial crisis where high unemployment resulted in increased bus usage. Other socio-economic variables have been shown to effect ridership locally (negatively and positively), e.g. share of foreign population (Gutiérrez et al., 2011; Taylor 
et al., 2009), gender balance (Chu, 2004), and age (Chiou et al., 2015). Hence, these are shown in Table 1 with both plus and minus signs.

The effects of private transport have most often been taken into account by aggregate car ownership rates or percentage of households without access to cars. However, in one study the motorcycle ownership was used as explanatory variable (Chiou et al., 2015). Generally, access to cars was associated with lower public transport ridership, and in many studies this has more impact on ridership than the characteristics of the public transport system itself (Taylor and Fink, 2013). However, a few exceptions exist. In four out of five Indian study areas public transport ridership was positively associated with the total number of vehicles, however also including buses (Rahman and Balijepalli, 2016), and in New York City and Hong Kong rail stations located in areas with higher car ownership had more passengers, arguably because of higher total trip rates for people owning a car (Loo et al., 2010). Finally, a general finding across studies was that costs of using private vehicles in terms of fuel prices or parking costs were associated with higher public transport ridership.

The effects of public transport characteristics have been analysed thoroughly in most studies including several indicators of public transport service quality, i.e. service coverage, service frequency (or the reciprocal service headway) and availability and amount of feeder services and transfer possibilities were all positively related to public transport ridership. Looking at the individual station level, a number of station-specific characteristics was found to be positively associated with public transport use including integrated ticketing (Crampton, 2002; Currie et al., 2011), availability of bicycle amenities (Blainey and Mulley, 2013; Zhao et al., 2013), and park-and-ride facilities for car users (Cervero et al., 2010; Guerra et al., 2012; Kuby et al., 2004). Finally, some studies also found significant positive effects of network characteristics in terms of centrality indicators. In Kuby et al. (2004) the normalised accessibility based on the average travel time to all other stations was positively related to station boardings. Other studies tested the influence of more in-depth network topology indicators on metro ridership. Sohn and Shim (2010) analysed station boardings on Seoul metro stations finding a positive influence of betweenness centrality, i.e. stations located on as many shortest paths through the network as possible. In addition, an indirect positive influence was found from straightness centrality, which measured whether routes from the station to other stations did not deviate from a virtual straight line, and from the average number of transfers from a station to all other stations in the network. Derrible and Kennedy (2009) analysed 19 subway systems from around the world and found that ridership was significantly positively related to three network topology indicators, namely i) network coverage, ii), directness measured as the number of lines divided by the maximum number of transfers from one vertex to another, and iii) connectivity measured as transfer possiblites.

To summarise the literature review much research has been devoted to identifying the main determinants of public transport ridership focusing on different aspects of socio-economic characteristics, land uses and attributes related to private and public transport. Most studies agree on the importance 
170 frequencies, widespread coverage and generally low travel times through the network. In this respect 171 network attributes ensuring good connections through the network such as many transfer possibilities 172 resulted in higher ridership suggesting the importance of well-connected networks. While these findings 173 are well documented no studies have fully analysed the influence of network topology and differences 174 across public transport modes on ridership in terms of individual public transport use frequency. This 175 present study addresses these shortcomings by jointly analysing per capita public transport ridership 176 across public transport modes and including network topology characteristics as well as taking into 177 account other main determinants identified by the literature review. 


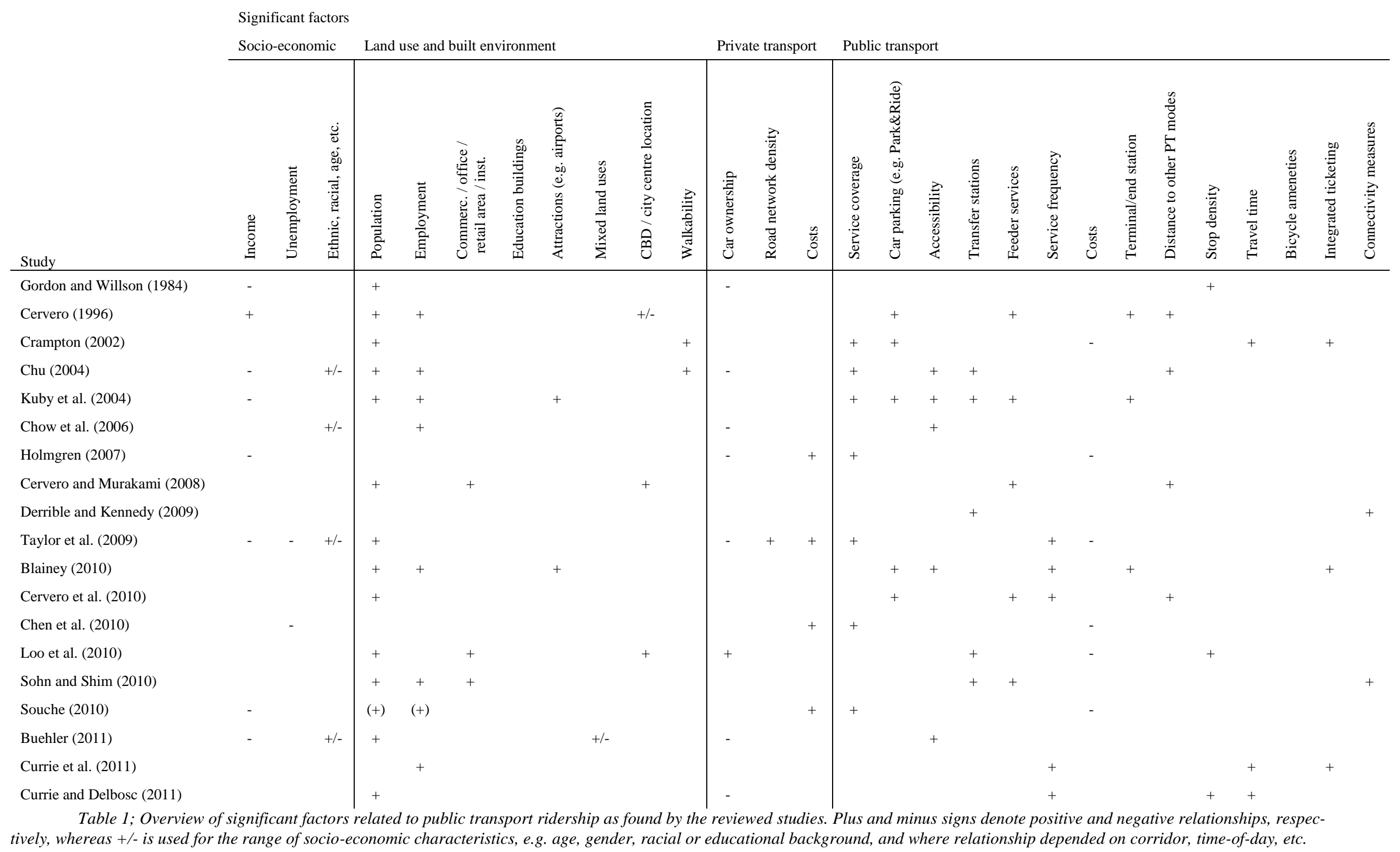




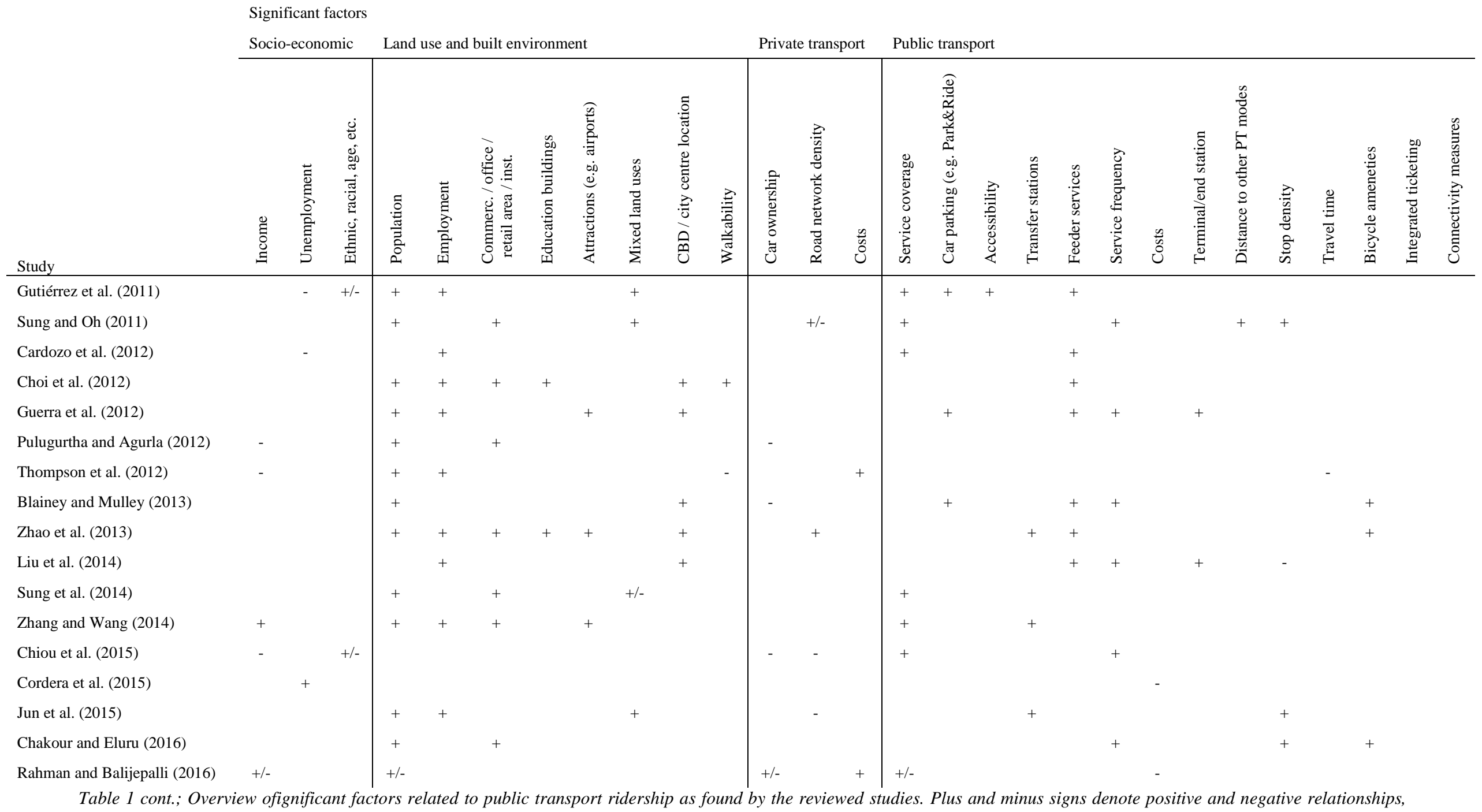

respectively, whereas +/- is used for the range of socio-economic characteristics, e.g. age, gender, racial or educational background, and where relationship depended on corridor, time-of-day, etc. 


\section{Data sources and measures}

To analyse the influence of various public transport networks on ridership and per capita use frequency a large database was collected consisting of urban demographics, network data characteristics, and economic variables for 48 European cities $^{2}$. The dataset including specification of data sources can be viewed in (dataset: Ingvardson and Nielsen, 2018).

The selection of cities, cf. Table 2, ensured a wide range of modal networks and network compositions. Many cities were historic cities as classified by Solís Trapero et al. (2015) with large regional and/or nationwide economic role, and where the public transport network played a large role in the formation of the city. But the sample also included medium-sized cities, all with metropolitan population above 150,000 inhabitants. In addition, some cities included all modes of public transport (metro, suburban rail, light rail, and bus), others included only different subsets of modes, and three cities included only buses. The large span in city sizes and network compositions ensured the possibility to identify impacts of the included variables.

\begin{tabular}{ll}
\hline Country & City \\
\hline Austria & Salzburg (S), Vienna (M,S,L) \\
Belgium & Antwerp (L), Brussels (M,L) \\
Czech Republic & Prague (M,L) \\
Denmark & Copenhagen (M,S), Odense, Aalborg, Aarhus \\
Finland & Helsinki (M,S,L) \\
France & Bordeaux (L), Lille (M,L), Lyon (M,L), Marseille (M,L), Nantes (L), Paris (M,S,L), \\
& Rennes (M), Strasbourg (L), Toulouse (M,L) \\
Germany & Berlin (M,S,L), Cologne (S), Dresden (S,L), Frankfurt am Main (M,S,L), Hamburg (M,S), \\
& Leipzig (S,L), Munich (M,S,L), Nuremberg (M,S,L) \\
Ireland & Dublin (S,L) \\
Netherlands & Amsterdam (M,L), Rotterdam (M,L) \\
Northern Ireland & Belfast (S) \\
Norway & Bergen (L), Oslo (M,S,L), Trondheim (L) \\
Portugal & Lisbon (M,S,L), Porto (S,L) \\
Spain & Barcelona (M,S,L), Madrid (M,S,L), Málaga (S), Palma de Mallorca (M), Sevilla (M,S,L) \\
Sweden & Gothenburg (L), Stockholm (M,S,L) \\
Switzerland & Bern (S,L), Lausanne (M,S), Zürich (S,L) \\
UK & London (M,S,L), Liverpool (S) \\
\hline \multicolumn{1}{c}{ Table 2; } & The 48 cities included in this study and their public transport networks. For each city it is noted whether \\
metro (M), suburban rail (S), and/or light rail networks (L) are included. Bus included for all cities.
\end{tabular}

\subsection{Urban demographics}

Strong relationship between land use and ridership were observed in all studies in the literature emphasising its importance in the dataset. Hence, population and employment densities were included in this study. Most previous studies included this directly from land use data based on a defined station

${ }^{2}$ As the study relied on data from 48 cities, each with ridership data from multiple transport service providers, the data sources are too extensive to be listed within this paper. Hence, all sources are listed in the attached data appendix. 
catchment area. However, as this study analysed ridership at an aggregate city-wide level the inclusion of population and employment densities was not straightforward. Efforts were made to collect these data ensuring comparability between the urban demographics and the actual service coverage area. However, data from national and regional statistics offices and public transport authorities often did not match due to differences between the area in which the public transport network is located and the administrative regions. Similar problems were experienced by Derrible and Kennedy (2009) who ended up using the simple mean of city population and metropolitan population as a proxy for the service coverage area for 15 of their 19 included cities. While being a practical approximation this study instead analysed the four distinct definitions of cities in Europe proposed by the EU Urban Audit 2012, namely i) the core city based on an administrative definition, ii) the Greater City making urbanised areas more comparable across regions, iii) commuting zones representing functional urban areas (Dijkstra and Poelman, 2012), and iv) high-density clusters based on coherent high-density urban statistical cells. The four measures were compared to the extent of the public transport networks for each urban area in the dataset. Based on these individual assessments no general designation could be made due to national differences in administrative borders of cities. Hence, a combined dataset was constructed based on all four measures by applying professional judgement. Data are available in Ingvardson and Nielsen (2018) [dataset].

\subsection{Public transport network characteristics}

Ridership data was collected through annual reports and statistics for the public transport agencies and authorities for the selected cities in the study. This was chosen due to limitations of other possible data sources such as the Millenium Cities database (Kenworthy and Laube, 2001) which are not current (data are from 1995 and 2010). By collecting the data directly from operators, it could be split between modes of transport so that light rail, suburban rail and metro networks were separated in order to analyse their different effects on ridership. This was important for two reasons. First, the capacity of the various systems are very different with metro carrying more passengers than light rail systems (Kittelson \& Associates et al., 2003). Secondly, the attractiveness of the various systems are often perceived differently by passengers due to varying speeds and/or comfort levels (Scherer and Dziekan, 2012). Hence, their influence on ridership might be different. It should be noted that the ridership figures for each mode are the number of boarding passengers. Hence, when evaluating total ridership there will be some double-counting as passengers transferring between different modes are counted twice. However, transfers within a single mode are usually counted as one boarding. The dataset also included network length and number of stations for each mode of the public transport network, and the service coverage was then calculated by dividing with the metropolitan area.

To analyse the influence of network topology two indicators were chosen based on the literature review, namely i) the number of transfer stations, and ii) the cyclomatic number of the network, i.e. the 
number of fundamental circuits. First, a significant parameter found across many studies was the possibility to transfer between lines as it ensures network robustness in terms of higher mobility through the network for passengers. Also, it was found specifically that the number of stations was more important for robustness than the total number of transfer options, i.e. two stations with two transfer options each are better than one station with four transfer options (Derrible and Kennedy, 2010). Second, this study included the cyclomatic number defined by the number of fundamental circuits in the network (Grubesic et al., 2008; Zhang et al., 2015). This was chosen as a network robustness indicator due to its simplicity while still indicating mobility in terms of travel opportunities as well as general network robustness. Other network indicators such as the betweenness centrality or the node degree mentioned by Cats (2016) could have been used, however due to a lack of digital representations of the 48 city networks this was not possible. Instead calculations were performed manually. For the number of terminals in the public transport networks the main focus was on transfer possibilities. Hence, for networks where multiple lines run in parallel through two stations the number of terminals is only regarded as one. This applies for several networks, e.g. the Copenhagen metro and the Lille light rail. The rationale was that despite the possibility of transferring at multiple stations there is in reality only one possible transfer between the two lines. Hence, this was counted as one terminal, except for longer parallel segments through three or more stations where it was counted as two terminals. This was due to passengers arriving from each end of the line probably perceiving this as two distinct transfer possibilities. The number of fundamental circuits in the network was similarly measured manually based on official network maps of the respective systems. As the network indicators were included to take into account network connectivity it was important to consider not only single-mode networks. Hence, they were measured based on the combined metro and suburban rail networks. However, the light rail network was not considered due to having access to combined network maps for only a few cities in the database.

\subsection{Availability of other transport modes}

To capture the effects of competing modes data on both car and bicycle accessibility were included. For car accessibility this included the car ownership rates at the urban level (Eurostat) and the daily Traffic Index taken from TomTom GPS devices ${ }^{3}$ (TomTom International BV, 2013). The latter was an indicator of daily urban road congestion defined as the percent extra time spent daily on urban roads and highways as compared to uncongested conditions. By this, data on the availability of cars and the accessibility of the road network is included, both highlighted to be main determinants of public transport ridership from the literature review. For bicycles, it was not possible to collect data on bicycle usage. Instead dummy variables were created based on whether the city was among the top 20 bicyclefriendly cities according to the Copenhagenize index (Copenhagenize, 2013).

${ }^{3}$ This data was available for all cities except Aalborg. Hence, the congestion level was assumed to be the average of the slightly larger Danish city Aarhus and the slightly smaller city of Odense. 


\subsection{Economic characteristics}

A number of socio-economic indicators were collected to take into account the economic differences between cities. Based on the literature review income was a dominant variable making it im-

268 portant to include. It was decided to use the aggregate measure of GDP per capita to measure the eco-

269 nomic development of the area. It would have been preferable to use a GDP indicator which also takes

270 into account purchasing power, but this data was not available at the metropolitan level. Hence, it was

271 prioritised to capture differences across cities in the same country by using the simple GDP per capita

272 indicator (Nielsen et al., 2014). As several of the studies in the literature found significant effects of 273 low-income households it was prioritised to include the unemployment rate and the GINI-coefficient,

274 both taken from Eurostat. These indicators were hypothesised to be related to the percent low-income 275 households thereby accounting for such effects.

\section{$276 \quad 3.5 \quad$ Sample statistics}

277 The variables included with their summary statistics are shown in Table 3, while Figure 1 and 278 Figure 2 illustrate the ridership and coverage of each rail mode across the cities. Generally, the intensity 279 of metro and suburban rail coverage per $\mathrm{km}^{2}$ strongly influence ridership - not only within these modes, 280 but also in general. Cities with no rail coverage have quite low overall public transport ridership, i.e. all 281 cities with more than 400 annual boardings per capita have metro or suburban rail networks whereas 282 many of those with fewer than 200 annual boardings per capita rely only on bus and light rail transit. 283 Specifically, the three Danish cities relying only on bus-based public transport attract less than 100 284 boardings per capita per year whereas cities with all public transport modes such as Paris, London and 285 Madrid attracts annual per capita boardings of 4-600. These observations are confirmed by the statistical 286 analysis in the following sections. 


\begin{tabular}{|c|c|c|c|c|}
\hline & Mean & Std. Dev. & Min & Max \\
\hline \multicolumn{5}{|l|}{ Dependent variable } \\
\hline Yearly public transport boardings per capita & 340.77 & 225.87 & 30.44 & $1,049.55$ \\
\hline \multicolumn{5}{|l|}{ Explanatory variables - urban demographics } \\
\hline Population density $\left[\mathrm{per} \mathrm{km}^{2}\right]$ & $2,399.31$ & $1,711.14$ & 169.01 & $8,478.24$ \\
\hline Job density $\left[\right.$ per $\left.\mathrm{km}^{2}\right]$ & 683.94 & 756.24 & 8.73 & $3,930.24$ \\
\hline \multicolumn{5}{|l|}{ Explanatory variables - network characteristics } \\
\hline Metro length $\left[\mathrm{km} / \mathrm{km}^{2}\right]$ & 0.09 & 0.11 & 0 & 0.47 \\
\hline Metro stations [stations per $\mathrm{km}^{2}$ ] & 0.10 & 0.13 & 0 & 0.40 \\
\hline Suburban railway length $\left[\mathrm{km} / \mathrm{km}^{2}\right]$ & 0.47 & 0.71 & 0 & 3.44 \\
\hline Suburban railway stations [stations per $\mathrm{km}^{2}$ ] & 0.17 & 0.24 & 0 & 0.98 \\
\hline Light rail length $\left[\mathrm{km} / \mathrm{km}^{2}\right]$ & 0.15 & 0.19 & 0 & 0.75 \\
\hline Light rail stations [stations per $\mathrm{km}^{2}$ ] & 0.35 & 0.56 & 0 & 2.58 \\
\hline Cyclomaticity [circuits $/ \mathrm{km}^{2}$ ] & 0.01 & 0.02 & 0 & 0.09 \\
\hline Terminals [per $\mathrm{km}^{2}$ ] & 0.02 & 0.03 & 0 & 0.11 \\
\hline \multicolumn{5}{|l|}{ Explanatory variables - Availability of other modes } \\
\hline Car ownership [vehicles per 1.000 inhabitants] & 401.51 & 82.11 & 233.40 & 570.50 \\
\hline TomTom Traffic Index [\% extra travel time due to congestion] & 25.31 & 5.90 & 14.00 & 39.00 \\
\hline \multicolumn{5}{|l|}{ Explanatory variables - Economic characteristics } \\
\hline GDP per capita $[1,000 \$]$ & 39.31 & 13.05 & 16.98 & 63.39 \\
\hline GINI coefficient & 28.86 & 3.05 & 22.70 & 34.20 \\
\hline Unemployment rate [\%] & 10.44 & 6.23 & 1.90 & 31.40 \\
\hline
\end{tabular}

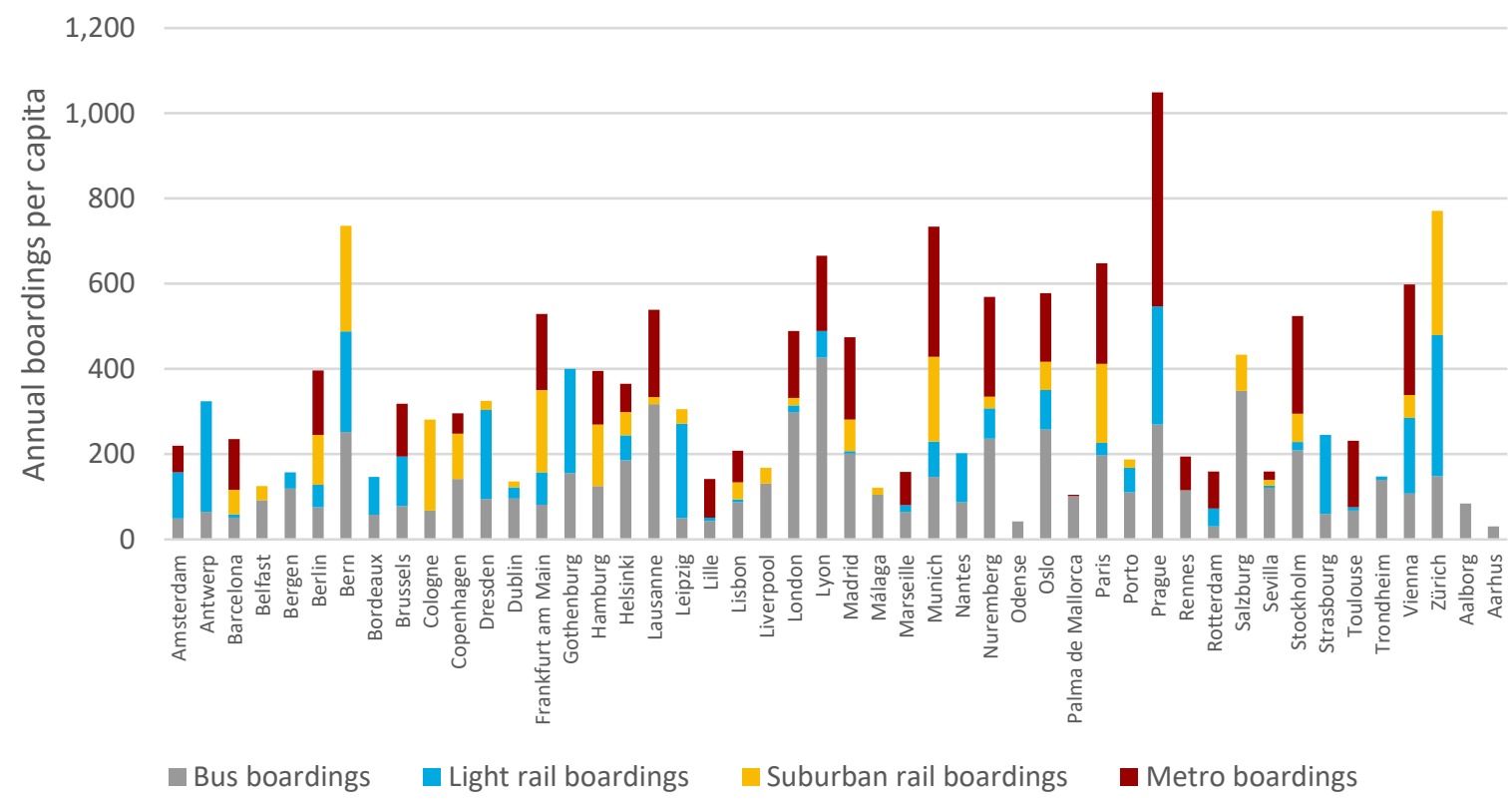

Figure 1; Public transport ridership by mode for the 48 cities included in this study. 

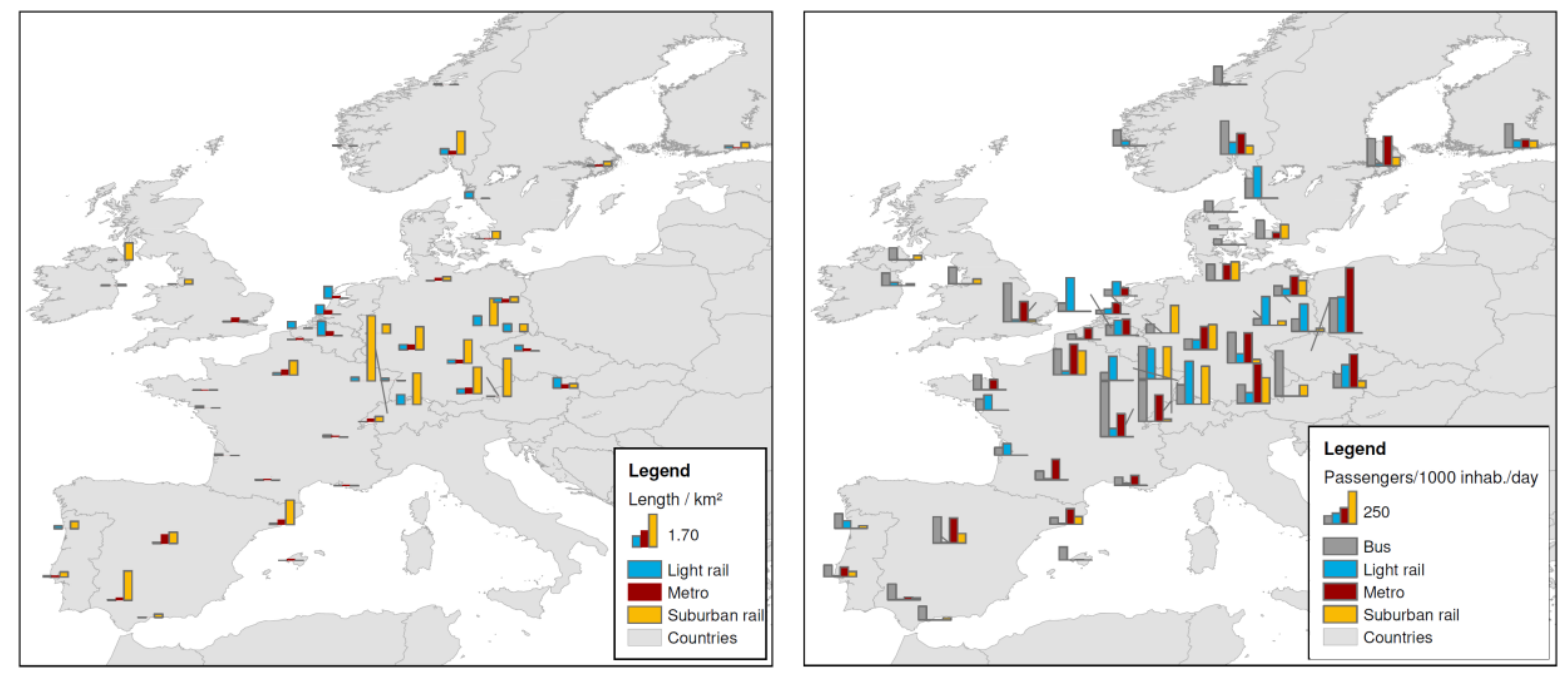

Figure 2; Rail-based network densities (metro, suburban rail and light rail transit) and per capita ridership for the same systems.

Figure 3 illustrates population density, job density, length of rail-based public transport, and public transport trip frequency across the cities in the study. Visually, a quite clear relationship between the density of rail-based public transport networks and ridership can be seen. A similar, but weaker, relationship can also be seen between the urban density and the density of the rail-based public transport network and the ridership. This indicates the clear positive relationship between dense cities, dense railbased public transport systems, and ridership, whereas more "sprawled" cities with less dense rail-based public transport systems have lower ridership.
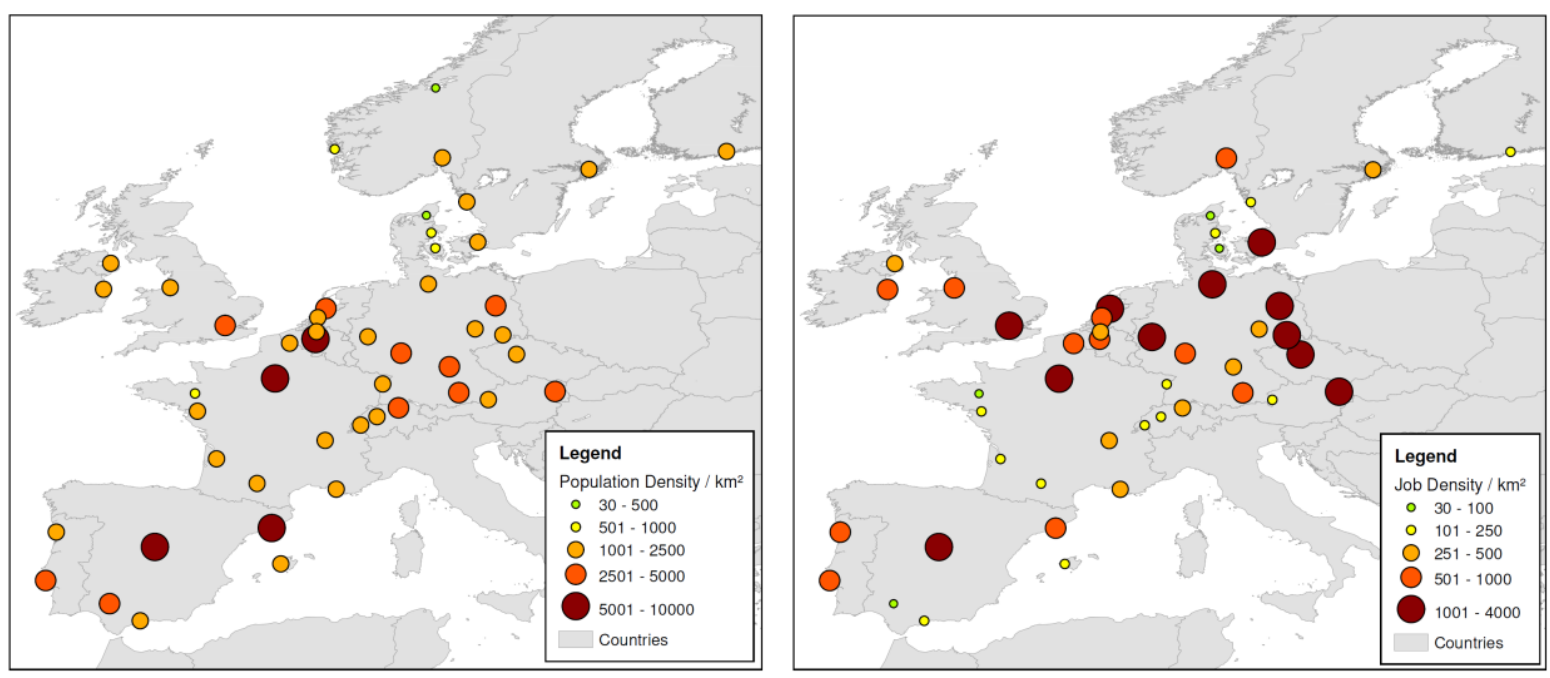

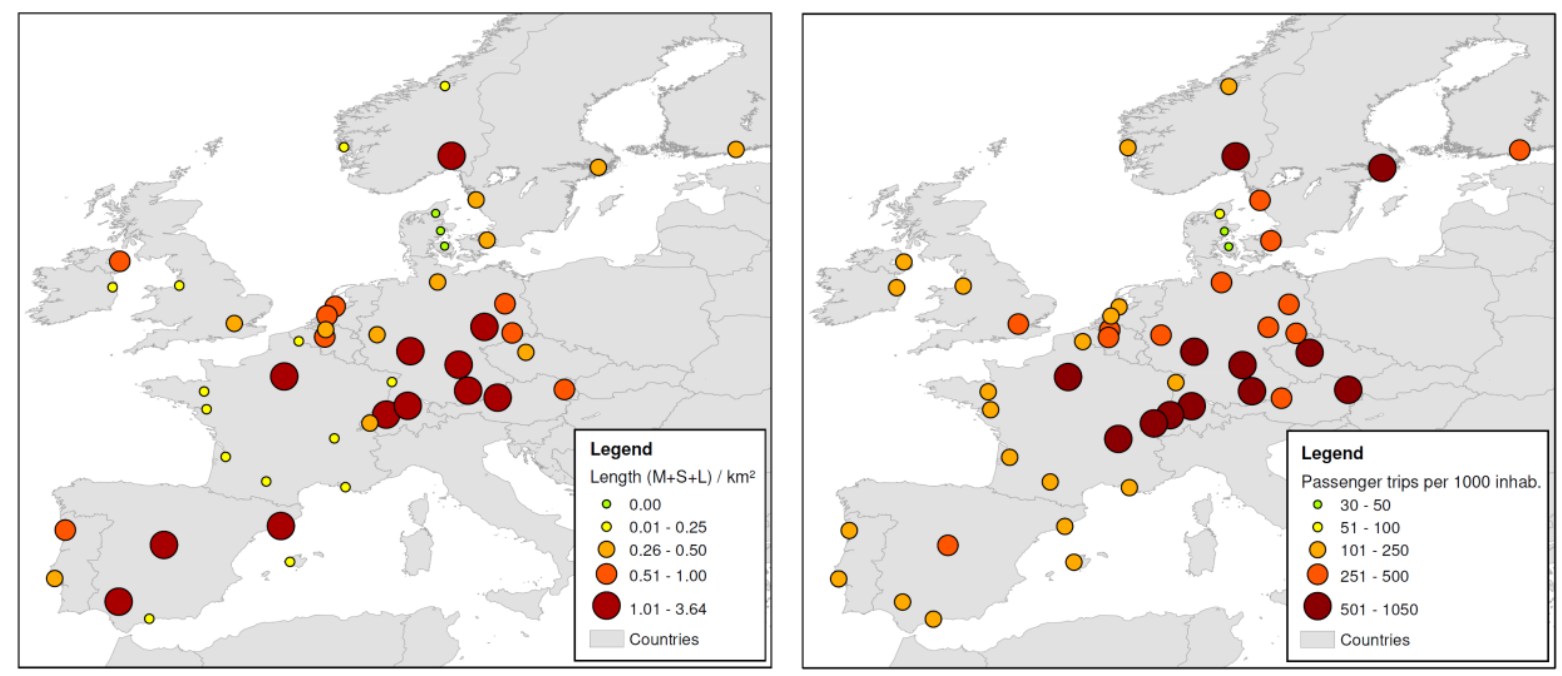

Figure 3; Maps of population density, job density, length of rail-based public transport per $\mathrm{km}^{2}$ (metro + suburban railways + light rail) and annual per capita public transport ridership.

Figure 4 illustrates the positive relationship between network indicators, network coverage, urban density and public transport ridership. Hence, people make more public transport trips per year in metropolitan areas with denser rail networks in terms of rail network coverage, e.g. density of rail stations. This is the case for the network indicators and the coverage of rail networks, i.e. the combined metro and suburban rail network.

More dense cities are associated with higher per capita ridership, emphasizing the importance of compact cities in generating public transport. Similar to previous research density of workplaces seems to have a larger influence on ridership. The influence of density on ridership is further highlighed when examining the relationship between ridership and both population density and logarithm of the population size. 

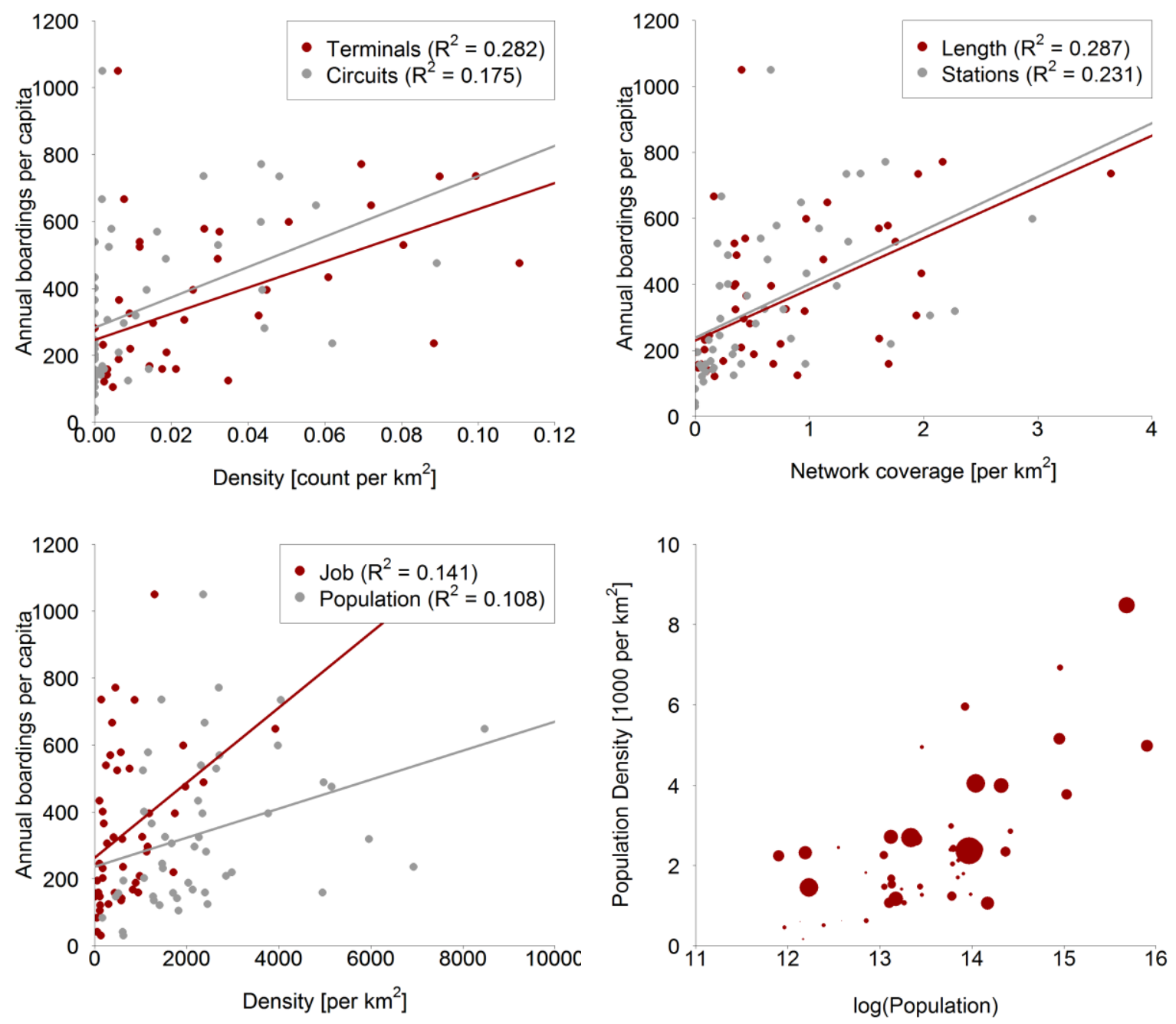

Figure 4; The relationship between per capita ridership and network density in terms of network indicators (upper left), rail network coverage (upper right), and urban density (below left). And relationship between population density and city size with size of dots representing ridership (below right).

\section{Analyses and results}

The study used the traditional approach of multiple linear regression models based on OLS in order to study the relationship between per capita public transport ridership and the urban demographics, public transport network, and socio-economic characteristics. Possible country-specific and regional ${ }^{4}$ fixed effects were taken into account by adding dummy variables. This was preferred over the increasingly popular GWR method because of the hypothesis of similarities being more pronounced between cities of the same country than solely being based on geographical distances between observations.

Due to the small sample size two sets of regression models were estimated, the first set being based on the raw dataset, and the second set being based on factor analysis and factor scores. The latter

${ }^{4}$ Six regions were defined: Scandinavia (Sweden, Norway, Denmark, Finland), Iberian Peninsula (Spain, Portugal), Central Europe (Germany, Austria, Switzerland, France), Eastern Europe (Czech Republic), Benelux (Belgium, Netherlands), and British Isles (UK, Ireland and Northern Ireland). 
option was chosen to reduce the number of explanatory variables thereby obtaining a higher degree of freedom in the regression (Crampton, 2002). This approach was similar to that of other studies where multiple variables were reduced to fewer factors which was then regressed on the observed dependent variable of ridership (Estupiñán and Rodríguez, 2008; Kobayashi and Lane, 2007; Syed and Khan, 2000). The approach was adopted for the 15 continuous explanatory variables whereas dummy variables were added in the final multiple regression analysis.

\subsection{Initial multiple linear regression}

Two separate model formulations were tested based on two distinct indicators of public transport network coverage: network length density (cf. Table 4) and station density (cf. Table 5). The models were estimated using the SAS/STAT software, Version 9.4 (SAS Institute Inc., 2008). All models were estimated with and without controlling for country and regional fixed effects, and the selection of significant variables was performed using manual selection based on backward elimination with a minimum significance level of $95 \%$ for all variables (except fixed effects). Insignificant variables are not reported. Note that the dependent variable is the total number of public transport trips (boardings) per capita per year.

\begin{tabular}{lrrrrrr}
\hline Variable & \multicolumn{2}{c}{ Model I-A } & \multicolumn{2}{c}{ Model I-B } & \multicolumn{2}{c}{ Model I-C } \\
\cline { 2 - 7 } & Coefficient & t-value & Coefficient & t-value & Coefficient & t-value \\
\hline Metro coverage $\left[\mathrm{km} / \mathrm{km}^{2}\right]$ & - & - & $645.65^{* * *}$ & 3.22 & $799.86^{* * *}$ & 4.35 \\
Suburban rail coverage $\left[\mathrm{km}^{2} / \mathrm{km}^{2}\right]$ & $165.98^{* * *}$ & 4.98 & $68.53^{* *}$ & 2.27 & $106.32^{* * *}$ & 3.55 \\
Light rail coverage $\left[\mathrm{km} / \mathrm{km}^{2}\right]$ & - & - & - & - & $312.76^{* *}$ & 2.22 \\
Job density [1.000 per km $\left.{ }^{2}\right]$ & $0.19^{* * *}$ & 5.24 & - & - & - & - \\
GDP per capita [1,000\$] & - & - & $0.006^{* *}$ & 2.58 & - & - \\
Car ownership [per 1.000 inhabitants] & $1.09^{* * *}$ & 3.21 & - & - & - & - \\
GINI coefficient & $-29.58^{* * *}$ & -3.71 & - & - & - & - \\
Constant & $544.70^{* *}$ & 2.26 & -153.48 & -1.40 & $225.60^{* * *}$ & 5.72 \\
\hline Country fixed effects & No & \multicolumn{3}{c}{ No } \\
Regional fixed effects & No & 48 & Yes & Yes \\
\hline $\mathrm{N}$ & 0.504 & 48 & 48 \\
$\mathrm{R}^{2}$ & \multicolumn{3}{c}{0.794} & \multicolumn{2}{c}{0.675} \\
\hline
\end{tabular}




\begin{tabular}{|c|c|c|c|c|c|c|}
\hline \multirow[t]{2}{*}{ Variable } & \multicolumn{2}{|c|}{ Model II-A } & \multicolumn{2}{|c|}{ Model II-B } & \multicolumn{2}{|c|}{ Model II-C } \\
\hline & Coefficient & t-value & Coefficient & t-value & Coefficient & t-value \\
\hline Metro coverage [stations per $\mathrm{km}^{2}$ ] & $813.95 * *$ & 2.67 & $470.74 * *$ & 2.46 & $708.65 * * *$ & 4.22 \\
\hline $\begin{array}{l}\text { Suburban rail coverage [stations per } \\
\mathrm{km}^{2} \text { ] }\end{array}$ & $471.71 * * *$ & 4.41 & $273.76 * *$ & 2.41 & $382.68 * * *$ & 4.18 \\
\hline Population density [1.000 per $\left.\mathrm{km}^{2}\right]$ & $-0.06^{* *}$ & -2.26 & - & - & - & - \\
\hline Job density $[1.000$ per km²] & $0.18^{* * *}$ & 3.32 & $0.07 * *$ & 2.08 & - & - \\
\hline Car ownership [per 1.000 inhabitants] & $0.80 * *$ & 2.22 & - & - & - & - \\
\hline Constant & -113.29 & -0.70 & 72.03 & 1.18 & $234.33 * * *$ & 5.56 \\
\hline Country fixed effects & No & & Yes & & No & \\
\hline Regional fixed effects & No & & No & & Yes & \\
\hline $\mathrm{N}$ & 48 & & 48 & & 48 & \\
\hline $\mathrm{R}^{2}$ & 0.431 & & 0.719 & & 0.627 & \\
\hline
\end{tabular}

Generally, only few variables showed significance at the 95\% significance level, especially when including fixed country or regional effects. This could suggest large variation in the data which cannot solely be explained by the included variables, i.e. idiosyncrasy. Per capita ridership was positively associated with network coverage with metro being mostly correlated. This emphasises the role of metro networks in attracting high ridership. But it is probably also a result of metro networks being implemented in metropolitan areas where there is a higher potential for passengers due to increased urban density. Suburban rail coverage was also positively associated with ridership, but the lower parameter estimates suggest a weaker correlation with per capita ridership.

Job density showed a stronger correlation with ridership than population density, which confirmed the initial data analysis. This could suggest a larger importance of urban density at the destination-end of a trip, which most often is the workplace. However, both were insignificant when taking into account country and regional differences explicitly using dummy variables. Car ownership was positively associated with ridership in Models I-A and II-A. This finding was somewhat surprising as most previous studies identified a negative correlation. However, it might be due to income on an aggregate level generally increase transport activities as also found by Zhang and Wang (2014). The GINIcoefficient was negatively associated with per capita ridership suggesting lower public transport usage in cities with higher economic inequality. This result probably covers two opposite effects, namely (i) that high inequality might lead to less travel activity, including less public transport usage, due to affordability issues faced by the residents, and (ii) that cities with higher inequality might have a larger share of low-income residents which tend to use public transport more often. Hence, the results suggest the first effect to be larger for the cities included in the analysis. However, it could also be related to the large number of Scandinavian cities, which are characterised by low economic inequality and high public transport usage, especially considering that these effects were insignificant when controlling for 
371 fixed geographical effects resulting in models solely based on network coverage, and job density and/or 372 GDP per capita.

373 Finally, the models showed slightly better fit when basing network coverage on length rather 374 than the number of stations. This could be due to long networks reaching a larger demand area, even 375 with fewer stops and increased access times, hence attracting greater ridership than shorter networks 376 with many stations. While being more accessible for passengers a higher density of stations will result 377 in lower speeds, hence creating a less attractive travel option compared to other travel modes.

378

379

380

381

382

383

384

385

386

387

388

389

\subsection{Factor analysis}

The full survey dataset showed good sampling adequacy with Kaiser-Meyer-Olkin $(\mathrm{KMO})=$ 0.70 . The determinant of the Spearman correlations matrix equalled $2.538 * 10^{-7}$ indicating existence of correlations without multi-collinearity, and the hypothesis of an identity correlations matrix was rejected using the Bartlett's test for sphericity. Based on the scree plot and an eigenvalue criteria of 1, four factors were extracted using principal components with orthogonal Varimax rotation, cf. Table 6. Dominant items were defined as those with an absolute value greater than 0.30 with each item only being allowed in one factor (Kline, 1994). The resulting factors also showed good internal consistency as standardised Cronbach's alpha's were all above 0.70 (Miller, 1995). The four factors together explained $78 \%$ of the variation in the variables with all communalities larger than 0.60 , except for car ownership at 0.45 and the congestion level at only 0.28 . Except for these two variables the factors were appropriate for factor regression (Maccallum et al., 1999).

\begin{tabular}{lrrrrr}
\hline & $\begin{array}{c}\text { F1 } \\
\text { Metro network, } \\
\text { connectivity and } \\
\text { urban density }\end{array}$ & $\begin{array}{c}\text { Suburban } \\
\text { rail net- } \\
\text { work }\end{array}$ & $\begin{array}{c}\text { F3 } \\
\text { Economic } \\
\text { inequality }\end{array}$ & $\begin{array}{c}\text { Light rail } \\
\text { network }\end{array}$ & Communality \\
\hline Population density & $\mathbf{0 . 8 8}$ & 0.20 & 0.17 & 0.17 & 0.87 \\
Metro network, length & $\mathbf{0 . 8 6}$ & 0.15 & 0.00 & 0.15 & 0.78 \\
Job density & $\mathbf{0 . 8 3}$ & -0.09 & -0.19 & 0.07 & 0.74 \\
Metro network, stations & $\mathbf{0 . 8 3}$ & 0.15 & 0.00 & 0.23 & 0.76 \\
Masks / cyclomatic number & $\mathbf{0 . 7 4}$ & 0.49 & 0.03 & 0.03 & 0.79 \\
TomTom congestion level & $\mathbf{0 . 5 1}$ & -0.06 & -0.03 & -0.11 & 0.28 \\
Suburban railway, length & 0.01 & $\mathbf{0 . 9 6}$ & -0.01 & 0.05 & 0.93 \\
Suburban railway, stations & 0.03 & $\mathbf{0 . 9 4}$ & -0.11 & -0.03 & 0.91 \\
Terminals & 0.58 & $\mathbf{0 . 7 6}$ & -0.02 & 0.14 & 0.92 \\
Unemployment rate & 0.16 & -0.23 & $\mathbf{0 . 8 8}$ & -0.03 & 0.86 \\
GDP per capita (R) & 0.21 & 0.07 & $-\mathbf{0 . 8 2}$ & 0.06 & 0.73 \\
GINI coefficient & 0.30 & 0.15 & $\mathbf{0 . 7 9}$ & -0.32 & 0.84 \\
Car ownership & -0.40 & 0.07 & $\mathbf{0 . 5 3}$ & -0.02 & 0.45 \\
Light rail, length & 0.10 & 0.05 & -0.17 & $\mathbf{0 . 9 4}$ & 0.93 \\
Light rail, stations & 0.16 & 0.04 & -0.09 & $\mathbf{0 . 9 4}$ & 0.91 \\
\hline Eigenvalue & 5.22 & 2.75 & 2.22 & 1.51 & - \\
Std. Cronbach's alpha & 0.89 & 0.91 & 0.78 & 0.94 & - \\
Average communality & - & - & - & - & 0.78 \\
\hline
\end{tabular}


The first factor contained the variables related to the dense metro networks, land use density in terms of population and employment, and high road congestion level, hence it is associated with dense urban areas which is often correlated with the presence of metro networks and congested road networks. The second factor was related to the suburban rail network, and also contained the connectivity indicator of number of terminals. Note that this variable also had a high loading on the first factor. The third factor was associated with the three variables related to economic performance, and car ownership. Finally, the fourth factor contained the two variables related to light rail networks.

The main model results based on factor loadings confirmed the expected correlations between per capita public transport ridership and the various explanatory variables, cf. Table 7. Higher per capita ridership was seen in cities with dense urban structure and presence of metro, suburban and light rail networks whereas economic inequality was associated with lower ridership. These main results were consistent across the three models when controlling for country-specific or regional fixed-effects. However, the significance of the factors decreased to the $90 \%$ level for Model I-B while economic inequality was insignificant in Model I-C. Hence, the results suggest that the regional dummy variables capture regional economic differences. Finally, no effects were observed for bicycle-friendly cities in any of the models.

\begin{tabular}{|c|c|c|c|c|c|c|}
\hline \multirow[b]{2}{*}{ Variable } & \multicolumn{2}{|c|}{ Model III-A } & \multicolumn{2}{|c|}{ Model III-B } & \multicolumn{2}{|c|}{ Model III-C } \\
\hline & Coefficient & t-value & Coefficient & t-value & Coefficient & t-value \\
\hline terminals & $97.27 * * *$ & 3.68 & $56.49^{* *}$ & 2.07 & $85.72 * * *$ & 3.55 \\
\hline F3 - Economic inequality & $-57.63 * *$ & -2.18 & $-145.64 *$ & -1.82 & -57.64 & -1.28 \\
\hline F4 - Light rail network & $54.66 * *$ & 2.07 & $60.65^{*}$ & 1.95 & $56.64 * *$ & 2.10 \\
\hline Country fixed effect & \multicolumn{2}{|l|}{ No } & \multicolumn{2}{|l|}{ Yes } & \multicolumn{2}{|l|}{ No } \\
\hline Regional fixed effect & \multicolumn{2}{|l|}{ No } & \multicolumn{2}{|l|}{ No } & \multicolumn{2}{|l|}{ Yes } \\
\hline Constant & $340.77 * * *$ & 13.03 & $97.29 *$ & 1.02 & $388.36 * * *$ & 13.02 \\
\hline $\mathrm{N}$ & \multicolumn{2}{|l|}{48} & \multicolumn{2}{|l|}{48} & \multicolumn{2}{|l|}{48} \\
\hline $\mathrm{R}^{2}$ & \multicolumn{2}{|l|}{0.357} & \multicolumn{2}{|c|}{0.761} & \multicolumn{2}{|c|}{0.663} \\
\hline
\end{tabular}

The results also show a positive influence of network connectivity measured by the two indi410 cators of the cyclomatic number and the number of transfer stations. The precise estimate of their indi411 vidual influence cannot readily be observed from the results. However, the results from the correlation 412 matrix in Table 8 showed that the number of terminals had higher correlation with per capita ridership 413 than the cyclomatic number. This finding is more evident when controlling for the socio-economic 414 variables. Hence, this not only confirms the importance of transfer stations in a network, but also sug- 
gests that transfer stations are more important in explaining ridership than the network topology indicator of cyclomatic number. However, it should be noted that it is not possible to infer causality based on these analyses.

\begin{tabular}{crr}
\hline & Cyclomatic number & Terminals \\
\hline Public transport ridership & $0.418(0.208)$ & $0.531(0.428)$ \\
\hline Table 8; Correlations between network topology indicators and ridership (conditional on population and job den-
\end{tabular}

Finally, due to the low communality of both variables related to car accessibility in the fourfactor model, i.e. car ownership and road congestion, another model was tested based on adding a fifth factor. This resulted in car ownership and the congestion level loading highly on the fifth factor while the remaining factors remained unchanged. Hence, the fifth factor was associated with low car ownership and high road congestion. The resulting regression analysis based on the five factors showed similar results, however with the fifth factor of car accessibility becoming insignificant, thus suggesting low correlation between car accessibility and per capita public transport usage for the urban areas included in this study.

\subsection{Study limitations}

While this study has given important insights into the complex relationship between aggregate determinants of per capita public transport ridership across 48 European metropolitan areas, the study is not without limitations which future studies could address.

Firstly, the analyses performed in this study are solely of a correlational nature based on crosssectional data. While such data can provide insights into the relationship between variables, no causational relationships can be inferred from the analysis. Hence, future research is necessary for analysing the causal relations between per capita public transport ridership and the characteristics related to the network and urban structure of the metropolitan areas.

Secondly, the literature review identified a large number of variables influencing public transport ridership in terms of urban demographics, public transport network characteristics, availability of other transport modes, and economic characteristics. While this study incorporated the most important variables within each of these categories, other variables could have been included. However, as the study analyses per capita public transport ridership in larger metropolitan areas on an aggregate level it was a deliberate focus to only collect the most important characteristics because of sample size and data collection constraints.

Nevertheless, important indicators such as the prices of public transport and car transport could have improved the analysis. As the literature review revealed these are important determinants of individual travel mode choice and aggregate usage rates. Hence, including one or several aggregate price indicators in terms of local prices for using a car or the fare level of the public transport system could potentially improve the analysis. However, for this study such data were not readily available. 
Another indicator to be included in future studies is the number of commuters in and into the metropolitan area as commuting patterns differ across cities, e.g. the degree to which the area attracts commuters from outside the area. This study did put emphasis on ensuring consistency between the definition of the urban area and the extent of the public transport network, but the number of commuters in and into the area is likely to differ across the included cities. Hence, the number of commuters could contribute to considerably higher ridership of the public transport system, especially for cities with attractive high-speed rail services (HSR) as these might trigger the emergence of discontinuous catchment areas for the metropolitan area (Mohíno et al., 2016). Also, some of the cities in the dataset, e.g. Amsterdam and Rotterdam (and each other), are located in close proximity to neighbouring cities, which facilitates strong commuting patterns using regional rail services. In terms of analysing the ridership per capita it can be argued whether to include commuters from outside the metropolitan areas, but it would be preferable to also include ridership for regional rail passengers within the metropolitan area. However, as it was not possible to get such specific data for the mentioned cities regional rail ridership was not included.

Furthermore, other variables related to the extent and availability of road network could possibly have improved the analysis. Considering the insignificance of the included congestion levels based on the TomTom Traffic Index collected through GPS devices (TomTom International BV, 2013), it might have been relevant to include the road network density similarly as the rail network density.

Thirdly, the dataset included a subset of 48 European metropolitan areas, which by definition is a small sample considering the number of variables included. While the sample did constitute cities of various sizes in terms of population and geographic extent, and with different types of public transport networks, the type of city was not considered specifically. More explicitly, there might well be differences if comparing ridership in metropolitan areas, e.g. those in this study, with that of cities with more intermediary roles serving larger metropolitan areas (Solís Trapero et al., 2015). However, as this study specifically defined the urban areas based on Dijkstra and Poelman (2012), which explicitly considers regional commuting patterns, such intermediary cities were not included in the dataset. However, future studies could analyse specifically how per capita use frequency of the public transport system differ across such city types.

Furthermore, cities might have different investment strategies in terms of developing their public transport network. Cities in which public transport modal shares are already high might be less encouraged to invest heavily in improved public transport, e.g. new metro or rail lines. Reversely, increased urban density and economic growth might lead to expanding the public transport network leading to increased ridership, and per capita use frequency. While such individual indicators were included in this study, the mechanisms in terms of a possible positive feedback loop could not be investigated in details using cross-sectional data. Hence, future studies could analyse more specifically 
possible differences across city types and explicitly control for different investment strategies. However, for such analysis it might be appropriate to investigate fewer cities in greater detail rather than an aggregate analysis as performed in this study.

Finally, the results of the initial regression analyses using individual characteristics revealed that only few variables were significantly related to per capita public transport ridership, especially when including regional or country fixed effects. This could suggest the existence of idiosyncrasy, which might be due to local differences across the metropolitan areas not represented by the included indicators. Hence, future studies could add other characteristics including the above-mentioned, e.g. indicators related to fare levels, car prices, bicycle amenities, and/or add more cities to get further insights into these relationships.

\section{Conclusions}

This study analysed the determinants of per capita public transport ridership across 48 European cities using aggregate data with specific focus on the influence of different public transport networks and network topology. The database collected as part of the study included detailed information about the public transport networks split between each of the three main public transport modes, i.e. metro, suburban rail, and light rail transit, as well as the most important urban and socio-economic characteristics identified by a thorough literature review of 36 previous studies.

An important finding from the data collection process was the importance of defining urban agglomerations and urban density consistently for analyses of urban public transport ridership. Based on multiple data sources the OECD-EC definition (Dijkstra and Poelman, 2012) was found to be the most consistent representation of the actual urban area. However, manual corrections still had to be made to ensure consistency between the definition of the urban area and the coverage of the public transport network.

The results of the two-fold multiple regression analysis based on the raw database and a factor analysis across the 48 cities confirmed the positive relationship between public transport coverage and ridership, consistent with findings in previous studies of individual cities. However, this study specifically found that the extent of metro, suburban and light rail networks were significantly related to ridership in terms of per capita usage rate. Hence, extensive rail network coverage is positively related to more frequent use of the public transport system thus highlighting its importance for ensuring sustainable mobility in large metropolitan areas. The intial regression models showed metro having the largest correlation suggesting the importance of metro networks for carrying large passenger numbers. The factor models showed the largest correlation from factors related to metro network and suburban rail, but with light rail also being positively associated with ridership. However, it should be noted that the factor related to metro network coverage also incorporated urban density due to the high correlation between these variables. This highlights the mutual dependence between urban density and metro network coverage. Dense metropolitan areas need metro networks to ensure high-capacity, fast and reliable 
transport. Similarly, the high construction costs of metro networks require dense urban areas in order to ensure sufficient potential ridership.

Network connectivity was analysed specifically in terms of network topology and transfer possibilities. While previous studies found significant influence of network topology indicators this study didn't find specific evidence of ridership being influenced by cyclicity or transfer stations. However, the factor analyses showed high correlation between network connectivity and network coverage, which together were strongly associated with ridership. In addition, analyses of correlations suggested a larger influence from the number of transfer possibilities on ridership rather than network topology measures such as the cyclomatic number. This suggests the importance of ensuring transfer possibilities in public transport networks thereby increasing mobility of passengers resulting in higher attractiveness of the entire system.

Finally, as expected differences between cities in terms of socio-economic characteristics also had significant influence on ridership. While not showing statistical influence individually in the initial regression analyses a combined effect of economic inequality was found to influence ridership negatively, suggesting that cities with larger equality have higher ridership. More specifically, lower unemployment, lower GINI-coefficient, and higher per capita GDP were associated with higher ridership. These effects were greatly reduced when taking into account geographical fixed effects in the models. Hence, the regional dummy variables seemed to capture large proportions of the economic differences across cities.

\section{References}

Blainey, S., 2010. Trip end models of local rail demand in England and Wales. J. Transp. Geogr. 18, 153-165. https://doi.org/10.1016/j.jtrangeo.2008.11.002

Blainey, S., Mulley, C., 2013. Using Geographically Weighted Regression to forecast rail demand in the Sydney Region, in: Australasian Transport Research Forum 2013 Proceedings. Brisbane, Australia, pp. 1-16.

Buehler, R., 2011. Determinants of transport mode choice: a comparison of Germany and the USA. J. Transp. Geogr. 19, 644-657. https://doi.org/10.1016/j.jtrangeo.2010.07.005

Cadarso, L., Marín, Á., Maróti, G., 2013. Recovery of disruptions in rapid transit networks. Transp. Res. Part E Logist. Transp. Rev. 53, 15-33. https://doi.org/10.1016/j.tre.2013.01.013

Cardozo, O.D., García-Palomares, J.C., Gutiérrez, J., 2012. Application of geographically weighted regression to the direct forecasting of transit ridership at station-level. Appl. Geogr. 34, 548-558. https://doi.org/10.1016/j.apgeog.2012.01.005

Cats, O., 2016. The robustness value of public transport development plans. J. Transp. Geogr. 51, 236246. https://doi.org/10.1016/j.jtrangeo.2016.01.011

Ceder, A. (Avi), Coriat, C., Le Net, Y., 2009. Measuring Public Transport Connectivity Performance Applied in Auckland, New Zealand. Transp. Res. Rec. J. Transp. Res. Board 2111, 139-147. 
Cervero, R., 1996. Commuter and Light Rail Transit Corridors: The Land Use Connection.

Cervero, R., Murakami, J., 2008. Rail + Property Development: A model of sustainable transit finance and urbanism. Berkeley, California, USA.

Cervero, R., Murakami, J., Miller, M., 2010. Direct Ridership Model of Bus Rapid Transit in Los Angeles County, California. Transp. Res. Rec. J. Transp. Res. Board.

Chakour, V., Eluru, N., 2016. Examining the influence of stop level infrastructure and built environment on bus ridership in Montreal. J. Transp. Geogr. 51, 205-217. https://doi.org/10.1016/j.jtrangeo.2016.01.007

Chen, C., Varley, D., Chen, J., 2010. What Affects Transit Ridership? A Dynamic Analysis involving Multiple Factors, Lags and Asymmetric Behaviour. Urban Stud. 48, 1893-1908. https://doi.org/10.1177/0042098010379280

Chiou, Y.-C., Jou, R.-C., Yang, C.-H., 2015. Factors affecting public transportation usage rate: Geographically weighted regression. Transp. Res. Part A Policy Pract. 78, 161-177. https://doi.org/10.1016/j.tra.2015.05.016

Choi, J., Lee, Y.J., Kim, T., Sohn, K., 2012. An analysis of Metro ridership at the station-to-station level in Seoul. Transportation (Amst). 39, 705-722. https://doi.org/10.1007/s11116-011-9368-3

Chow, L.-F., Zhao, F., Liu, X., Li, M.-T., Ubaka, I., 2006. Transit Ridership Model Based on Geographically Weighted Regression. Transp. Res. Rec. 1972, 105-114.

Chu, X., 2004. Ridership Models at the Stop Level. Tampa, FL.

Copenhagenize, 2013. The Copenhagenize Bicycle-friendly Cities Index 2013 [WWW Document]. URL http://copenhagenize.eu/index/ (accessed 10.20.17).

Cordera, R., Canales, C., Dell 'olio, L., Ibeas, A., 2015. Public transport demand elasticities during the recessionary phases of economic cycles. Transp. Policy 42, 173-179. https://doi.org/10.1016/j.tranpol.2015.05.022

Crampton, G., 2002. International Comparison of Urban Light Rail Systems: the roles of integrated ticketing, pedestrianisation, and population density, in: Proceedings of the ERSA 2002 Conference, Dortmund, Germany. Dortmund, Germany, p. Paper 167.

Currie, G., Ahern, A., Delbosc, A., 2011. Exploring the drivers of light rail ridership: An empirical route level analysis of selected Australian, North American and European systems. Transportation (Amst). 38, 545-560. https://doi.org/10.1007/s11116-010-9314-9

Currie, G., Delbosc, A., 2011. Understanding bus rapid transit route ridership drivers: An empirical study of Australian BRT systems. Transp. Policy 18, 755-764. https://doi.org/10.1016/j.tranpol.2011.03.003

Derrible, S., Kennedy, C., 2010. The complexity and robustness of metro networks. Phys. A Stat. Mech. its Appl. 389, 3678-3691. https://doi.org/10.1016/j.physa.2010.04.008

Derrible, S., Kennedy, C., 2009. Network Analysis of World Subway Systems Using Updated Graph Theory. Transp. Res. Rec. J. Transp. Res. Board 2112, 17-25. https://doi.org/10.3141/2112-03 
Dijkstra, L., Poelman, H., 2012. Cities in Europe: The New OECD-EC Definition. Brussels, Belgium.

Estupiñán, N., Rodríguez, D.A., 2008. The relationship between urban form and station boardings for

Bogotá's BRT. Transp. Res. Part A Policy Pract. 42, 296-306. https://doi.org/10.1016/j.tra.2007.10.006

Gordon, P., Willson, R., 1984. The Determinants of Light-Rail Transit Demand - An International Cross-Sectional Comparison. Transp. Res. Part A Gen. 18A, 135-140.

Grubesic, T.H., Matisziw, T.C., Murray, A.T., Snediker, D., 2008. Comparative Approaches for Assessing Network Vulnerability. https://doi.org/10.1177/0160017607308679

Guerra, E., Cervero, R., Tischler, D., 2012. Half-Mile Circle: Does It Best Represent Transit Station Catchments? Transp. Res. Rec. J. Transp. Res. Board 101-109. https://doi.org/10.3141/2276-12

Gutiérrez, J., Cardozo, O.D., García-Palomares, J.C., 2011. Transit ridership forecasting at station level: an approach based on distance-decay weighted regression. J. Transp. Geogr. 19, 1081-1092. https://doi.org/10.1016/j.jtrangeo.2011.05.004

Hadas, Y., Ranjitkar, P., 2012. Modeling public-transit connectivity with spatial quality-of-transfer measurements. J. Transp. Geogr. 22, 137-147. https://doi.org/10.1016/j.jtrangeo.2011.12.003

Holmgren, J., 2007. Meta-analysis of public transport demand. Transp. Res. Part A Policy Pract. 41, 1021-1035. https://doi.org/10.1016/j.tra.2007.06.003

[dataset] Ingvardson, J.B., Nielsen, O.A., 2018. Public transport network and ridership data for 48 European metropolitan areas, Mendeley Data, v1. http://dx.doi.org/10.17632/j362v5x3nk.1

Jun, M.-J., Choi, K., Jeong, J.-E., Kwon, K.-H., Kim, H.-J., 2015. Land use characteristics of subway catchment areas and their influence on subway ridership in Seoul. J. Transp. Geogr. 48, 30-40. https://doi.org/10.1016/j.jtrangeo.2015.08.002

Kaplan, S., Popoks, D., Prato, C.G., Ceder, A. (Avi), 2014. Using connectivity for measuring equity in transit provision. J. Transp. Geogr. 37, 82-92. https://doi.org/10.1016/j.jtrangeo.2014.04.016

Kenworthy, J., Laube, F., 2001. The Millennium Cities Database for Sustainable Transport.

Kittelson \& Associates, KFH Group, Parsons Brinckerhoff Quade \& Douglass, Hunter-Zaworski, K., 2003. Transit Capacity and Quality of Service Manual (TCRP Report 100), TCRP Report. Transportation Research Board.

Kline, P., 1994. An easy guide to factor analysis. Routledge, London, UK.

Kobayashi, T., Lane, B., 2007. Spatial Heterogeneity and Transit Use, in: Paper for 11th World Conference on Transportation Research. Berkeley, California, USA.

Kuby, M., Barranda, A., Upchurch, C., 2004. Factors influencing light-rail station boardings in the United States. Transp. Res. Part A Policy Pract. 38, 223-247. https://doi.org/10.1016/j.tra.2003.10.006

Liu, C., Ma, T., Erdogan, S., Ducca, F.W., 2014. How to Increase Rail Ridership in Maryland? Direct Ridership Models (DRM) for Policy Guidance, in: Paper Compendium of the 93rd Annual 
Loo, B.P.Y., Chen, C., Chan, E.T.H., 2010. Rail-based transit-oriented development: Lessons from New York City and Hong Kong. Landsc. Urban Plan. 97, 202-212. https://doi.org/10.1016/j.landurbplan.2010.06.002

Maccallum, R.C., Widaman, K.F., Zhang, S., Hong, S., 1999. Sample Size in Factor Analysis. Psychol. Methods 4, 84-99.

Miller, M.B., 1995. Coefficient Alpha: A Basic Introduction from the Perspectives of Classical Test Theory and Structural Equation Modeling. Struct. Equ. Model. 2, 255-273.

Mohíno, I., Ureña, J.M., Solís, E., 2016. Transport infrastructure and territorial cohesion in rural metroadjacent regions: A multimodal accessibility approach. The case of Castilla-La Mancha in the context of Madrid (Spain). J. Transp. Geogr. 57, 115-133. https://doi.org/10.1016/j.jtrangeo.2016.10.001

Nielsen, O.A., Rich, J., Pedersen, T.R., 2014. Trans-Tools 3 - Data description.

Pulugurtha, S., Agurla, M., 2012. Assessment of Models to Estimate Bus-Stop Level Transit Ridership using Spatial Modeling Methods. J. Public Transp. 15, 33-52. https://doi.org/10.5038/23750901.15.1.3

Rahman, S., Balijepalli, C., 2016. Understanding the determinants of demand for public transport: Evidence from suburban rail operations in five divisions of Indian Railways. Transp. Policy 48, 13-22. https://doi.org/10.1016/j.tranpol.2016.02.006

SAS Institute Inc., 2008. SAS/STAT ® 9.2 User's Guide - The REG Procedure.

Scherer, M., Dziekan, K., 2012. Bus or Rail: An Approach to Explain the Psychological Rail Factor. J. Public Transp. 15, 75-93. https://doi.org/10.5038/2375-0901.15.1.5

Sienkiewicz, J., Hoo, J.A., 2005. Statistical analysis of 22 public transport networks in Poland. Phys. Rev. 72, 046127.

Sohn, K., Shim, H., 2010. Factors generating boardings at Metro stations in the Seoul metropolitan area. Cities 27, 358-368. https://doi.org/10.1016/j.cities.2010.05.001

Solís Trapero, E., Sanz, I.M., Francés, J.M. de U., 2015. Global Metropolitan-Regional Scale in Evolution: Metropolitan Intermediary Cities and Metropolitan Cities. Eur. Plan. Stud. 23, 568596. https://doi.org/10.1080/09654313.2013.878691

Souche, S., 2010. Measuring the structural determinants of urban travel demand. Transp. Policy 17, 127-134. https://doi.org/10.1016/j.tranpol.2009.12.003

Sung, H., Choi, K., Lee, S., Cheon, S., 2014. Exploring the impacts of land use by service coverage and station-level accessibility on rail transit ridership. J. Transp. Geogr. 36, 134-140. https://doi.org/10.1016/j.jtrangeo.2014.03.013

Sung, H., Oh, J.-T., 2011. Transit-oriented development in a high-density city: Identifying its association with transit ridership in Seoul, Korea. Cities 28, 70-82. https://doi.org/10.1016/j.cities.2010.09.004 
Syed, S.J., Khan, A.M., 2000. Factor Analysis for the Study of Determinants of Public Transit Ridership. J. Public Transp. 3, 1-17.

Taylor, B.D., Fink, C.N.Y., 2013. Explaining transit ridership: What has the evidence shown? Transp. Lett. 5, 15-26. https://doi.org/10.1179/1942786712Z.0000000003

Taylor, B.D., Miller, D., Iseki, H., Fink, C., 2009. Nature and/or nurture? Analyzing the determinants of transit ridership across US urbanized areas. Transp. Res. Part A Policy Pract. 43, 60-77. https://doi.org/10.1016/j.tra.2008.06.007

Thompson, G., Brown, J., Bhattacharya, T., 2012. What Really Matters for Increasing Transit Ridership: Understanding the Determinants of Transit Ridership Demand in Broward County, Florida. Urban Stud. 49, 3327-3345. https://doi.org/10.1177/0042098012443864

TomTom International BV, 2013. TomTom Traffic Index [WWW Document]. URL https://www.tomtom.com/en_gb/trafficindex/ (accessed 4.3.18).

Zhang, D., Wang, X., 2014. Transit ridership estimation with network Kriging: a case study of Second Avenue Subway, NYC. J. Transp. Geogr. 41, 107-115. https://doi.org/10.1016/j.jtrangeo.2014.08.021

Zhang, X., Miller-Hooks, E., Denny, K., 2015. Assessing the role of network topology in transportation network resilience. J. Transp. Geogr. 46, 35-45. https://doi.org/10.1016/j.jtrangeo.2015.05.006

Zhao, J., Deng, W., Song, Y., Zhu, Y., 2013. What influences Metro station ridership in China? Insights from Nanjing. Cities 35, 114-124. https://doi.org/10.1016/j.cities.2013.07.002 